\title{
$\mathrm{FMCW}$ 레이다의 다수 표적 탐지 알고리즘 제안
}

\section{Multi-Target Detection Method Using FMCW and CW}

\author{
윤재혁 · 유승오 · 양재원 · 이동주 \\ Jaehyuk Yoon $\cdot$ Seongoh Yoo $\cdot$ Jaewon Yang $\cdot$ Dongju Lee
}

요 약

최근 레이다를 이용하여 표적을 실시간으로 탐지하고, 표적의 거리, 속도, 각도 정보 등을 추출하는 방법에 대해 많은 연구가 진행되고 있다 ${ }^{[1]}[3]$. 기존 주파수 변조 방식의 연속 신호 레이다는 하나의 표적을 탐지할 때 펄스 레이다에 비해 높은 거리 해상도와 높은 신호 대 잡음비(signal to noise ratio, 이하 SNR)를 장점으로 갖는다. 하지만, 다수 표적이 존재하 는 경우, 반사 신호의 도플러 효과에 의해 고스트 표적(Ghost target)이 발생하며, 오탐지(false detection) 문제를 발생시킨 다. 본 논문에서는 기본적인 주파수 변조 연속 신호(frequency modulation continuous waveform, 이하 FMCW)와 연속 신호 (continuous waveform, 이하 $\mathrm{CW}$ )를 이용한 방식을 소개하고, 제안하는 $\mathrm{FMCW}$ 와 $\mathrm{CW}$ 의 신호 처리 방식을 이용하여 다수 표적을 분리 탐지하고, 고스트 표적 신호를 제거하는 기법을 소개한다.

\section{Abstract}

Recently, many researches have been conducted on a method of extracting target distance, velocity, and angle information from a radar by detecting a target in real time. Conventional frequency-modulated continuous signal radars have the advantage of higher distance resolution and higher signal-to-noise ratio than pulse radar when detecting a single target. However, when multiple targets are present, Ghost targets are created by the Doppler effect of the reflected signal and cause a false detection problem. In this paper, we introduce a basic frequency modulated continuous signal and a continuous signal method, and introduce a technique for detecting multiple targets and removing Ghost target signals through the proposed FMCW and $\mathrm{CW}$ signal processing methods.

Key words: Multi-Target, FMCW, CW, Detection, Radar

\section{I. 서 론}

유도무기 및 총포탄약 비행시험에서 이벤트 및 자탄 분리 등 다수 표적 계측이 필요한 시험요구조건이 발생 되고 있다. 기존의 탐지 방식들은 차량의 이동환경에 맞 추어 설계된 방식으로써 $\mathrm{FMCW}$ 의 한 주기 내에서 거리
및 속도 변화가 없다는 가정 하에 검증되어 왔다. 하지만, 유도무기 및 총포탄약 비행시험의 경우 $\mathrm{FMCW}$ 의 한 주 기 내에서 표적의 거리 및 속도 변화가 크기 때문에 개선 된 처리방식이 필요하다.

$\mathrm{FMCW}$ 신호는 기본적으로 톱니(sawtooth), 삼각(triangular), 부등변 사각(trapezoid) 형태의 파형을 이용한다. 여기서

\footnotetext{
「이 연구는 국방과학연구소(Agency for Defense Development) 연구비로 연구되었음.」 국방과학연구소 5기술연구본부(The $5 \mathrm{R} \& \mathrm{D}$ Institute, Agency for Defense Development) - Manuscript received November 12, 2019 ; Revised January 6, 2020 ; Accepted January 14, 2020. (ID No. 20191112-120)

· Corresponding Author: Jae-Hyuk Yoon (e-mail: jh_yoon@add.re.kr, kgandtmac@gmail.com)
} 
각 파형들은 고유한 한계점을 갖는다. 톱니파의 경우, 신 호처리를 통해 얻은 거리 프로파일을 축적하고, 축적된 거리 프로파일을 FFT(Fast Fourier Transform) 연산하여 속 도 값을 구하는 방법을 사용한다. 하지만, 장거리 및 고속 표적은 톱니파의 변조 주기를 무한정 줄일 수 없기 때문 에 적용하기 어렵다. 삼각파의 경우, 고속 신호에도 적용 이 가능하나, 상승 첩(up-chirp)과 하강 첩(down-chirp) 간 에 발생하는 고스트 표적 신호를 제거하기 어려워 다수 표적 상황에 적용하기 어렵다. 부등변 사각파형 또한 거 리 정보와 속도 정보가 혼재되어 속도가 같은 다수 표적 에 의한 고스트 표적을 제거하기 어렵다.

$\mathrm{FMCW}$ 파형을 단독으로 사용할 경우, 앞서 설명한 문 제점들을 해결할 수 없으므로 새로운 탐지 방식이 필요 하다. 먼저, 기존의 다수 표적 탐지 알고리즘을 소개하고, 유도무기 및 총포탄약 비행시험에 맞는 환경에서 사용할 수 있는 알고리즘을 제안한다. 마지막으로 제안된 알고리 즘을 시뮬레이션을 통해 검증 결과를 소개한다.

\section{FMCW 레이다 배경이론}

일반적으로 FMCW 레이다의 다수 표적 탐지 알고리즘 은 크게 두 가지로 나뉜다. 연속된 고속 톱니파를 이용하 는 방식과 ${ }^{[4]}$, 기울기가 다른 $\mathrm{FMCW}$ 를 송신하여 다수 표 적 신호를 구별하는 방식이 있다 ${ }^{[5]}$.

첫 번째 방식인 고속 톱니파를 이용하는 경우, 그림 1 과 같이 짧은 주기를 갖는 톱니파 형태의 $\mathrm{FMCW}$ 신호를 연속으로 송수신하여 얻은 거리 프로파일을 생성한다. 변 조 주기는 속도 해상도를 높이기 위해선 CPI(Coherent Pulse Interval) 내에 최대한 많은 거리 프로파일을 생성해야 하

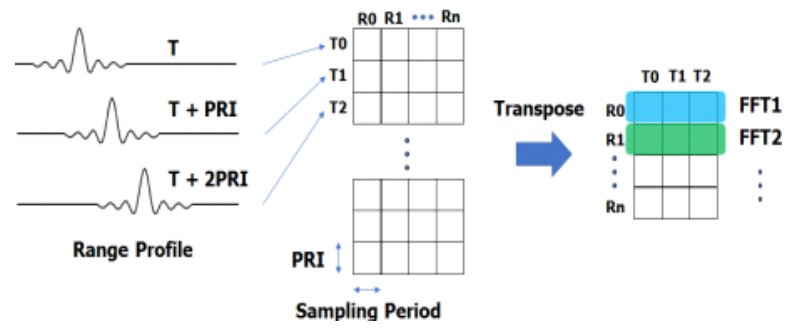

그림 1. 다수 고속 톱니파를 이용한 탐지방식

Fig. 1. Detection method using fast sawtooth waveform.
며, 짧은 PRI(Pulse Repetition Interval)을 갖는 톱니파를 사 용한다. 주로 PRI는 수십 $\mu s$ 내에서 설정하며, 상대적으 로 짧은 거리, 낮은 속도를 갖는 표적 신호 탐지에 적합하 며, 고속 표적을 탐지하기에 시간적으로 어려움이 있다. 장거리 표적 신호를 얻기 위해 긴 PRI를 사용할 경우, $\mathrm{CPI}$ 시간동안 같은 거리에 표적 신호가 존재하지 않고 이 동하기 때문에 속도 정보를 얻을 수 없게 된다. 또한 FFT 연산의 반복횟수가 많아지기 때문에 연산량이 많아지는 단점이 있다.

두 번째 방식인 기울기가 다른 삼각파를 이용하는 경 우, 그림 2(a)와 같이 표적이 하나일 때 기울기가 다른 삼 각 $\mathrm{FMCW}$ 를 통해서 총 4 개의 거리, 속도 정보가 포함된

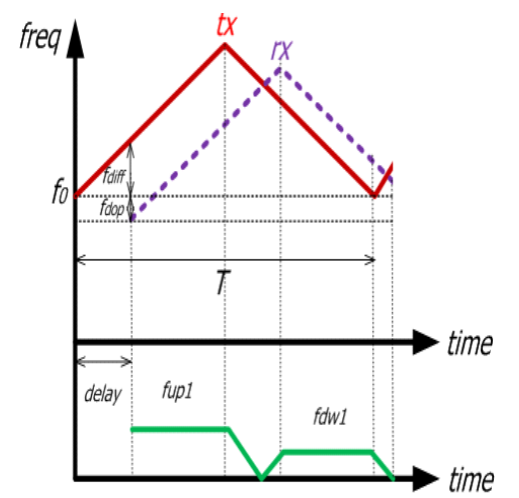

(a) 기울기가 다른 $\mathrm{FMCW}$ 를 이용한 탐지방식

(a) Detection method using various slope FMCW

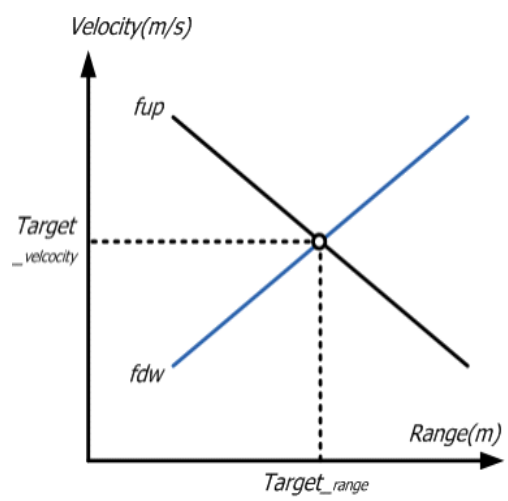

(b) 데이터 결합을 통해 표적 거리-속도 획득

(b) Acquisition of range-velocity with data association

그림 2. $\mathrm{FMCW}$ 를 이용한 기존 탐지 방식

Fig. 2. Convention detection technique of FMCW. 
비트주파수를 검출한다. 각 비트주파수를 첫 번째 삼각파 의 업 비트 주파수 $f_{u p 1}$, 다운 비트 주파수 $f_{d w 1}$, 변조 주 기 $T 1$, 두 번째 삼각파의 업 비트 주파수 $f_{u p 2}$, 다운 비 트 주파수 $f_{d w 2}$, 변조 주기 $T 2$, 중심 주파수 $f_{0}$, 도플러 주파수 $f_{d o p}$, 거리에 따른 주파수 차이 $f_{d i f f}$ 라고 정의하 고, 각 비트 주파수를 이용하여 데이터 결합함으로써 그 림 2(b)의 그래프로 표현할 수 있고, 이를 통해 표적의 거 리 및 속도 값을 구할 수 있다. 이 연산은 앞선 고속 톱니 파를 이용하는 방식에 비하여 상대적으로 연산량이 적다 는 점과 PRI를 길게 가져감으로써 장거리 표적을 추적 시 높은 SNR값을 가질 수 있다는 장점이 있다. 하지만, 이 방법 또한 다수 표적 추적을 할 때 같은 거리에 있는 표 적 간에 구분하기 어렵다는 단점이 있으며, 속도가 빠른 표적의 경우 긴 PRI 시간동안 축적된 $\mathrm{FFT}$ 결과에 의해 비트 주파수의 피크 점 검출에 어려움을 야기한다. 따라 서 본 논문에서는 이러한 단점들을 보완하고, 장거리 및 고속의 특징을 갖는 유도무기 및 총포탄약 시험에서 다 수 표적을 탐지하는 알고리즘을 제안한다.

먼저 III장에서는 제안하는 다수 표적 탐지 알고리즘을 설명하고, IV 장에서는 시뮬레이션을 통한 탐지 알고리즘 성능 검증 결과를 소개하며, $\mathrm{V}$ 장을 통해 결론 및 향후 연 구 진행방향을 보여주고자 한다.

\section{III. 제안된 다수 표적 탐지 알고리즘}

본 장에서는 제안된 탐지 알고리즘을 설명한다. 기본 적으로 삼각 $\mathrm{FMCW}$ 파형을 이용한 단일 표적의 거리-속 도 정보를 획득하는 방식을 설명하고, 제안된 파형을 소 개한 후 다수 표적 탐지 방식을 기술한다.

기본적인 기울기가 항상 같은 삼각파의 경우, 그림 2(a) 의 $f_{d i f f}$ 와 $f_{d o p}$ 를 이용하여 비트 주파수를 식 (1)과 같이 정의할 수 있다.

$$
\left\{\begin{array}{l}
f_{u p}=f_{d i f f}+f_{d o p} \\
f_{d w}=f_{d i f f}-f_{d o p}
\end{array}\right.
$$

도플러 주파수와 속도의 상관관계는 식 (2)로 정의된 다. $c$ 는 빛의 속도 $(\mathrm{m} / \mathrm{s}), v$ 는 표적의 상대 속도 $(\mathrm{m} / \mathrm{s})$ 이다.

$$
f_{d o p}=\frac{2 v f_{0}}{c}
$$

삼각 $\mathrm{FMCW}$ 의 기울기를 이용하여 $f_{d i f f}$ 를 정리하면 식 (3)으로 정의할 수 있다.

$$
f_{\text {diff }}=\frac{B^{*} \tau}{T / 2}=\frac{4 B R}{c T}
$$

여기서 $\tau$ 는 왕복시간(s)이며, $2 \mathrm{R} / \mathrm{c}$ 로 정의된다. $B$ 는 변조 대역폭 $(\mathrm{Hz}), R$ 은 거리 $(\mathrm{m})$ 이다.

식 (1)에 식 (2)와 식 (3)을 대입하여 $R$ 과 $v$ 에 관한 식으 로 정리하면 식 (4)와 같이 표현되며, 두 식을 $v$ 에 관한 식 으로 다시 정리하면 식 (5)를 얻을 수 있다.

$$
\begin{aligned}
& R=\frac{c T}{8 B}\left(f_{d w}-f_{u p}\right) \\
& v=\frac{c}{4 f_{0}}\left(f_{d w}+f_{u p}\right) \\
& v=\frac{1}{f_{0}}\left(\frac{c f_{u p}}{2}-\frac{2 B}{T}\right)
\end{aligned}
$$

상기 설명된 방식을 이용하여 단일 표적의 거리-속도 정보를 구할 수 있으나, 다수 표적의 경우 표적의 개수가 $N$ 개일 때 $N^{2}$ 만큼 표적 후보가 생성되기 때문에 적용하 기가 어렵다. 예를 들어 그림 3과 같이 표적 신호가 두 개 인 경우, $f_{u p}, f_{d w}$ 에 의해 고스트 표적을 포함하여 총 4 개의 표적 후보가 생성되기 때문이다. 검정색 선이 표적 1 에 대한 비트 주파수이고, 빨간색 선이 표적 2에 대한 비

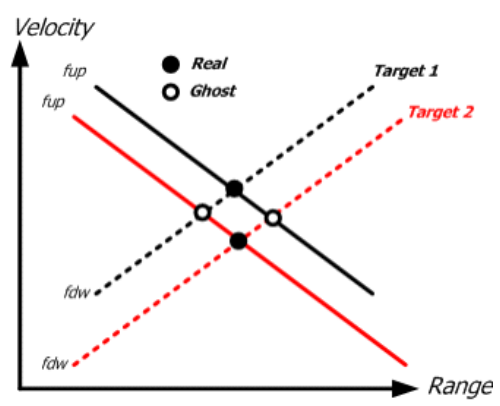

그림 3. 2개 표적이 존재할 때

Fig. 3. The case of two target in the beam. 
트 주파수이다. 기울기가 다른 두 개의 톱니파와 하나의 연속파를 혼합하여 이용하는 방식을 제안하며, 그림 4를 통해서 사용되는 파형을 확인할 수 있다. 제안된 파형을 이용하여 각 그래프의 교점을 찾는 방식으로 다수 표적 을 분리 탐지할 수 있다.

톱니파에 적용하기 위해 식 (4)의 두 식을 $R$ 에 대한 수 식으로 정리하면 식 (6)으로 표현할 수 있다.

$$
R=\frac{c T}{4 B}\left(f_{u p}-f_{d o p}\right)
$$

두 표적에 대한 파형 구성 및 비트 주파수 그리고 도플 러 주파수 신호를 그림 4와 같이 얻을 수 있으며, 이렇게 얻어진 값을 식 (6)에 대입하면 그림 5와 같은 그래프로 표현할 수 있다. 하지만, 그림 5 의 그래프에서 거리 혹은 속도의 모든 값을 비교하여 교점을 찾아내는 것은 많은 연산량이 필요하고, 실시간 처리하는데 어려움이 있다. 그러므로 연속파와 주파수 변조파 중 상대적으로 $\mathrm{SNR}$ 값 이 높은 연속파에 의해 분리 탐지된 표적만 제한적으로 연산을 수행하는 방식을 제안한다.

두 표적의 거리 및 속도를 각각 $(320 \mathrm{~m}, 700 \mathrm{~m} / \mathrm{s}),(360$ $\mathrm{m}, 705 \mathrm{~m} / \mathrm{s}$ )으로 설정하고, 파형은 표 2와 같이 사용하였

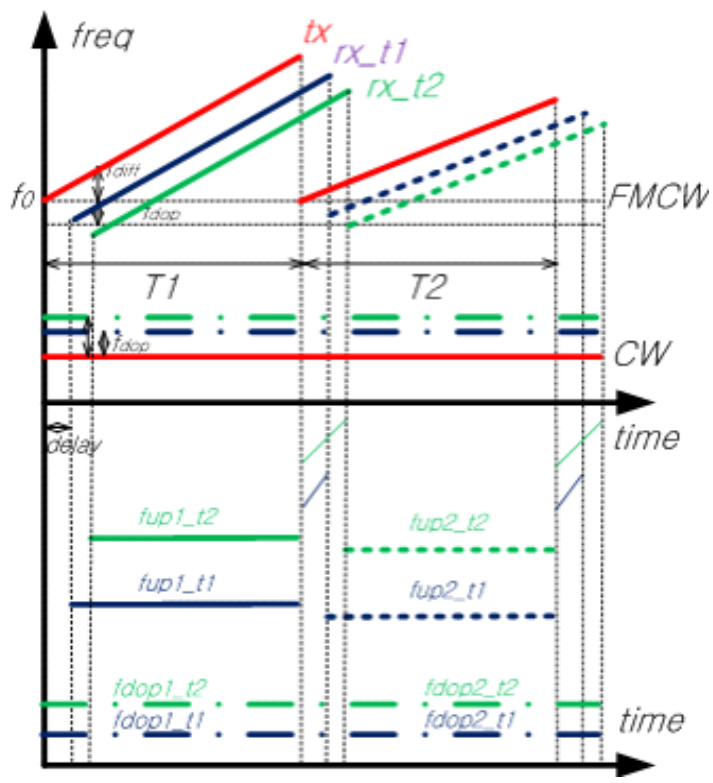

그림 4. 제안된 기울기가 다른 삼각파 및 연속파 구성 Fig. 4. Proposed configuration of waveform.

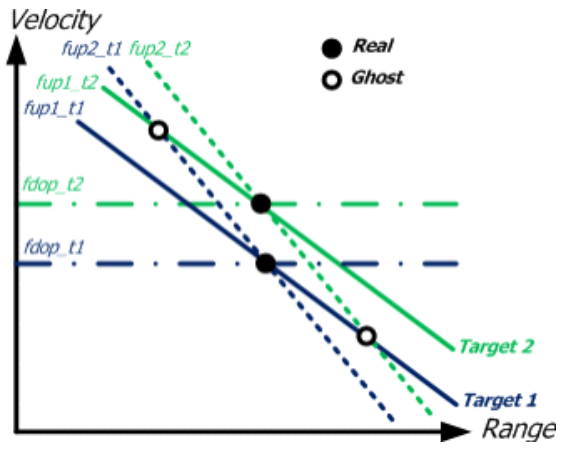

그림 5. 두 표적 조건에서 주파수 수신 결과

Fig. 5. The result of received signal with two targets.

을 때, 표 1 과 같이 연속파 $(\mathrm{CW})$ 를 통해 얻은 도플러 주파 수 $\left(f_{d o p}\right)$ 를 기준으로 2 개의 표적을 분리 탐지할 수 있다. 탐지된 두 개의 $f_{d o p}$ 값 중 하나의 값을 식 (6)에 대입하

표 1. 두 표적 신호 탐지 예

Table 1. Example of two target detection.

\begin{tabular}{|c|c|c|c|c|c|c|}
\hline \multirow[b]{2}{*}{$\begin{array}{c}\text { Detected } \\
\text { target }\end{array}$} & \multirow{2}{*}{\begin{tabular}{|c|}
$\mathrm{CW}$ \\
$f_{d o p}$ \\
$(\mathrm{kHz})$
\end{tabular}} & \multicolumn{2}{|c|}{ FMCW } & \multirow{2}{*}{\begin{tabular}{|c|}
$\mathrm{R}$ \\
$(\mathrm{m})$
\end{tabular}} & \multirow[b]{2}{*}{ Comparison } & \multirow[b]{2}{*}{ Result } \\
\hline & & $\begin{array}{c}\mathrm{B} \\
(\mathrm{MHz})\end{array}$ & $\begin{array}{c}f_{\text {up }} \\
(\mathrm{kHz})\end{array}$ & & & \\
\hline \multirow{8}{*}{$\begin{array}{c}\text { Target } \\
\# 1 \\
f_{\text {dop_t } 1} \\
(699.9 \\
\mathrm{m} / \mathrm{s})\end{array}$} & \multirow{8}{*}{48.9992} & \multirow{4}{*}{50} & $f_{u p 1 t 1}$ & \multirow{2}{*}{319.5} & $f_{u p 1 \_t 1}-f_{u p 2 \_t 1}$ & 0 \\
\hline & & & 57.5031 & & $f_{u p 1-t 1}-f_{u p 2 \_t 2}$ & 39.1 \\
\hline & & & $f_{\text {up } 1 t 2}$ & \multirow{2}{*}{358.9} & $f_{u p 1 \_t 2}-f_{u p 2 \_t 1}$ & 39.4 \\
\hline & & & 70.6414 & & $f_{u p 1-t 2}-f_{u p 2 \_t 2}$ & 0.3 \\
\hline & & \multirow{4}{*}{40} & $f_{\text {up } 2 t 1}$ & \multirow{2}{*}{319.5} & \multirow{2}{*}{\multicolumn{2}{|c|}{$\begin{array}{c}\text { Minimum value } \\
f_{u p 1 \_t 1}-f_{u p 2 \_t}\end{array}$}} \\
\hline & & & 36.2155 & & & \\
\hline & & & $f_{u p 2_{-} \_t}$ & \multirow{2}{*}{358.6} & \multirow{2}{*}{\multicolumn{2}{|c|}{$R=319.5 \mathrm{~m}$}} \\
\hline & & & 46.6348 & & & \\
\hline \multirow{8}{*}{$\begin{array}{c}\text { Target } \\
\# 2 \\
f_{\text {dop_t } t 2} \\
(704.9 \\
\mathrm{m} / \mathrm{s})\end{array}$} & \multirow{8}{*}{49.3492} & \multirow{4}{*}{50} & $f_{\text {up } 1 t 1}$ & \multirow{2}{*}{320.5} & $f_{u p 1 \_t 1}-f_{u p 2 \_t 1}$ & 0.4 \\
\hline & & & 57.5031 & & $f_{u p 1 \_t 1}-f_{u p 2 \_t 2}$ & 39.4 \\
\hline & & & $f_{\text {up } 1 t 2}$ & \multirow{2}{*}{359.9} & $f_{u p 1 \_t 2}-f_{u p 2 \_t 1}$ & 39 \\
\hline & & & 70.6414 & & $f_{u p 1 \_t 2}-f_{u p 2 \_t 2}$ & 0 \\
\hline & & \multirow{4}{*}{40} & $f_{\text {up } 2 t 1}$ & \multirow{2}{*}{320.9} & \multirow{4}{*}{\multicolumn{2}{|c|}{$\begin{array}{l}\text { Minimum value } \\
f_{u p 1 \leq 2}-f_{u p 2 t 2}\end{array}$}} \\
\hline & & & 36.2155 & & & \\
\hline & & & $f_{\text {up } 2_{-} t 2}$ & \multirow{2}{*}{359.9} & & \\
\hline & & & 46.6348 & & & \\
\hline
\end{tabular}


고, 주파수 변조파(FMCW)로부터 얻어진 비트 주파수 $\left(f_{u p}\right)$ 값을 차례로 대입하여 각 경우에 대한 거리 값 $(\mathrm{R})$ 을 계산한다. 그 후, 얻어진 $R$ 값을 서로 비교하여 가장 작은 차이 값을 갖는 경우의 $R$ 값을 표적의 거리 값으로 정의한 다.

높은 가속도를 갖는 표적의 경우, $T 1$ 와 $T 2$ 사이에 속 도 $\left(f_{d o p}\right)$ 의 변화가 생기게 되며 $R$ 값을 연산할 때 오차를 발생시킨다. 이러한 오차를 제거하기 위해 도플러 주파수 의 기울기를 통해 얻은 가속도 값을 이용하여 하나의 표 적에 대한 $T 1\left(f_{d o p 1}\right)$ 과 $T 2\left(f_{d o p 2}\right)$ 주기 내 속도를 따로 구하여 적용함으로써 오차를 최소화하였다.

\section{$\mathrm{N}$. 실험 결과}

모의실험의 표적은 자탄이 분리되는 탄을 기준으로 요 구조건을 선정하였으며, 다수 표적에 대한 요구조건은 현 재 군에서 운용 중인 $155 \mathrm{~mm} \mathrm{OOO}$ 탄을 기준으로 최대 표적 개수 8 개, 최대 거리 $10 \mathrm{~km}$, 분리 이후 최대 순간속 도 $1,500 \mathrm{~m} / \mathrm{s}$ 로 설정하였다. 모의실험의 매개변수는 표 2 를 통해서 확인할 수 있으며, 가상 표적에 대한 거리, 속 도 설정 값 및 모의실험 결과는 표 3 을 통해서 확인할 수 있다. 표 3의 결과는 잡음이 없는 상태에서의 결과이며, $\mathrm{SNR} 15 \mathrm{~dB}$ 환경에서 시뮬레이션해 보았을 때 탐지된 거 리, 속도에 오차가 발생할 뿐 8 개의 표적이 분리 탐지됨 을 확인할 수 있었다.

III 장에서 설명한 다수 표적 탐지 알고리즘을 LabVIEW 로 구현하여 모의실험 수행한 결과, 그림 6 과 같이 가상

표 2. 모의실험 매개변수

Table 2. Simulated parameters.

\begin{tabular}{|c|c|c|c|}
\hline \multicolumn{2}{|c|}{ Parameters } & Value & Unit \\
\hline \multirow{2}{*}{$\begin{array}{c}\text { FMCW } \\
\# 1\end{array}$} & $B$ & 50 & $\mathrm{MHz}$ \\
\cline { 2 - 4 } & Period & 5 & $\mathrm{msec}$ \\
\hline \multirow{2}{*}{$\begin{array}{c}\text { FMCW } \\
\# 2\end{array}$} & $B$ & 40 & $\mathrm{MHz}$ \\
\cline { 2 - 3 } & Period & 5 & $\mathrm{msec}$ \\
\hline \multicolumn{2}{|c|}{ Resolution of velocity } & 0.5 & $\mathrm{~m} / \mathrm{s}$ \\
\hline \multirow{2}{*}{$\begin{array}{c}\text { Center } \\
\text { frequency }\end{array}$} & FMCW & 10.501 & \multirow{2}{*}{$\mathrm{GHz}$} \\
\cline { 2 - 3 } & $\mathrm{CW}$ & 10.500 & \\
\hline
\end{tabular}

표 3. 표적의 거리 및 속도 설정 값

Table 3. Simulated range-velocity setting.

\begin{tabular}{|c|c|c|c|c|}
\hline & \multicolumn{2}{|c|}{ Virtual target info. } & \multicolumn{2}{c|}{ Simulation results } \\
\cline { 2 - 5 } & $\begin{array}{c}\text { Range } \\
(\mathrm{m})\end{array}$ & $\begin{array}{c}\text { Velocity } \\
(\mathrm{m} / \mathrm{s})\end{array}$ & $\begin{array}{c}\text { Range } \\
(\mathrm{m})\end{array}$ & $\begin{array}{c}\text { Velocity } \\
(\mathrm{m} / \mathrm{s})\end{array}$ \\
\hline Target \#1 & 10,000 & 200 & $9,999.82$ & 199.979 \\
\hline Target \#2 & 9,900 & 300 & $9,899.38$ & 299.978 \\
\hline Target \#3 & 9,800 & 500 & $9,797.82$ & 499.979 \\
\hline Target \#4 & 9,700 & 700 & $9,698.83$ & 699.988 \\
\hline Target \#5 & 9,600 & 750 & $9,598.74$ & 749.991 \\
\hline Target \#6 & 9,500 & 900 & $9,497.79$ & 899.994 \\
\hline Target \#7 & 9,400 & 1,100 & $9,398.77$ & $1,099.99$ \\
\hline Target \#8 & 9,200 & 1,500 & $9,197.73$ & $1,499.98$ \\
\hline
\end{tabular}

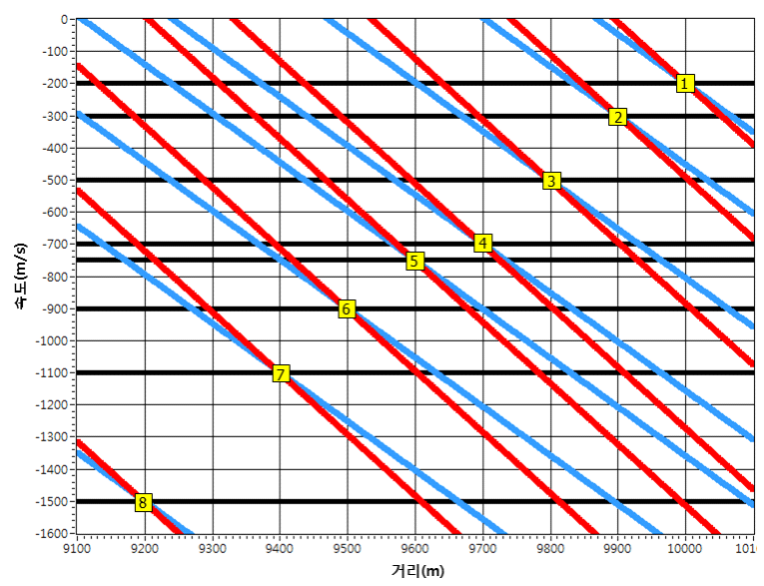

그림 6. LabVIEW를 이용한 다수 표적 조건에서 모의실험 결과

Fig. 6. The results of simulation for multi-target using LabVIEW.

표적에 의한 그래프를 획득할 수 있었다. 그림 6의 빨간 선은 $50 \mathrm{MHz}$ 대역폭 $\mathrm{FMCW}$ 신호의 비트 주파수에 의한 그래프, 파란선은 $40 \mathrm{MHz}$ 대역폭 $\mathrm{FMCW}$ 신호의 비트 주 파수에 의한 그래프, 검은선은 $\mathrm{CW}$ 신호에 의한 도플러 주 파수이다.

\section{V. 결 론}

본 논문에선 실제 군에서 사용되는 다탄두 무기의 이 벤트 및 자탄 분리 등에서 발생되는 거리, 속도 조건을 기 준으로 다수 표적을 분리 탐지하는 방법을 제안하였다. 
$\mathrm{LabVIEW}$ 언어를 기반으로 다수의 가상 표적의 거동 정 보를 설정하고, 신호처리를 통해 제안된 다수 표적 탐지 기술을 검증하였다. 현재 제작 중인 시제 레이다를 이용 해 실제 상황에서 제안된 알고리즘을 검증하고, 유도무기 및 총포탄약 시험에서 사용할 계획이다.

\section{References}

[1] W. Wang, J. Du, and J. Gao, "Multi-target detection method based on variable carrier frequency chirp sequence," Sensor, vol. 18, no. 10, p. s18103386, Oct. 2018.

[2] E. Hyun, Y. S. Jin, and J. H. Lee, "A pedestrian detection scheme using a coherent phase difference method based on 2D range-Doppler FMCW radar," Sensors, vol. 16, no.

윤 재 혁 [국방과학연구소/선임연구원]

http://orcid.org/0000-0002-7124-5879

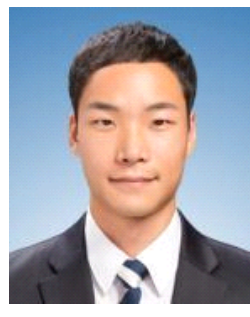

2012년: 숭실대학교 정보통신전자공학부 (공학사)

2014년: 숭실대학교 정보통신공학과 (공 학석사)

2014년 2016년: National Instruments Engineer

2016년 현재: 국방과학연구소 선임연구원 [주 관심분야] 레이다, $\mathrm{RF}$ 회로, 신호처리 등

\section{유 승 오 [국방과학연구소/선임연구원]}

http://orcid.org/0000-0003-0855-8247

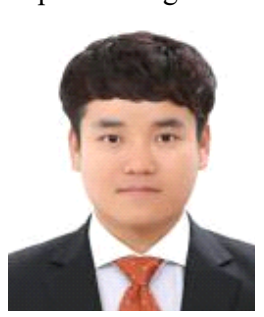

2010년: 충남대학교 전자전파정보통신공 학과 (공학사)

2012년: 충남대학교 전파공학과 (공학석사) 2012년 현재: 국방과학연구소 선임연구원 [주 관심분야] 레이다, RF 시스템 등
1, p. s16010124, 2016.

[3] M. Kronauge, H. Rohling, "New chrip sequence radar waveform," IEEE Transactions on Aerospace and Electronic Systems, vol. 50, no. 4, pp. 2870-2877, Oct. 2013.

[4] W. Sediono, "Method of measuring Doppler shift of moving targets using FMCW maritime radar," in Proceedings of 2013 IEEE International Conference on Teaching, Assessment and Learning for Engineering (TALE), Bali, 2013, pp. 378-381.

[5] E. Hyun, J. H. Lee, "A method for multi-target range and velocity detection in automotive FMCW radar," in 2009 12th International IEEE Conference on Intelligent Transportation Systems, St. Louis, MO, Oct. 2009, pp. $1-5$.

\section{양 재 원 [국방과학연구소/선임연구원]}

http://orcid.org/0000-0002-2553-2033

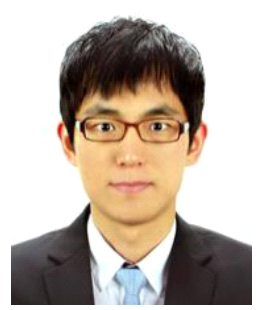

2011년: 서울과학기술대학교 전자공학과 (공학사)

2014년: 서울과학기술대학교 전자공학과 (공학석사)

2014년 현재: 국방과학연구소 선임연구원 [주 관심분야] 레이다, RF 회로, 신호처리 등 http://orcid.org/0000-0002-3398-5024

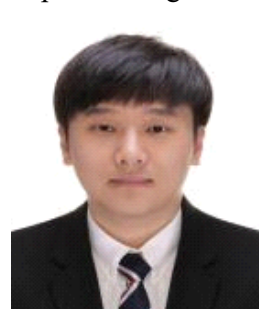

2015년: 중앙대학교 전자전기공학부 (공 학사)

2017년: 중앙대학교 전자전기공학과 (공 학석사)

2017년 현재: 국방과학연구소 연구원

[주 관심분야] 레이다, RF 시스템, 안테나 등 